\title{
TINJAUAN LITERATUR KOMPETENSI KEWIRAUSAHAAN PADA USAHA KECIL MENENGAH (UKM)
}

\author{
Farhan Maulana $^{1}$, Muhamad Rizal' ${ }^{2}$, Ria Arifianti ${ }^{3}$ \\ Ilmu Administrasi Bisnis, Fakultas Ilmu Sosial dan Ilmu Politik \\ Universitas Padjadjaran, Jalan Bukit Dago Utara No.25 \\ Email: farhan19001@mail.unpad.ac.id'1, m.rizal@unpad.ac.id², \\ r.arifianti@unpad.ac.id ${ }^{3}$
}

\begin{abstract}
Entrepreneurial competence is knowledge, attitudes and skills that are connected to one another, which is needed by entrepreneurs to be trained and developed in order to be able to produce the best performance in managing their business. In the activities of Small and Medium Enterprises (UKM), this entrepreneurial competence is also very necessary. Entrepreneurial competence is also rarely discussed, especially in SMEs. So, we discuss the classification, identification of several scientific publications and analyze the literature to create a detailed understanding of the entrepreneurial competence field in SMEs. We use the Systematic Mapping Study (SMS) method to examine various articles on entrepreneurial competence in SMEs based on the focus and type of research over time. The results show the categories and quantification of entrepreneurial competency studies into various dimensions, as well as an overview of current research topics and trends in entrepreneurial competence in SMEs.
\end{abstract}

Keywords: entrepreneurship competence, micro, small and medium enterprises, systematic mapping study.

\begin{abstract}
Abstrak
Kompetensi kewirausahaan merupakan pengetahuan, sikap dan keterampilan yang terhubung satu dengan lainnya, yang diperlukan pengusaha untuk dilatih dan dikembangkan agar mampu menghasilkan kinerja terbaik dalam mengelola usahanya. Di dalam aktivitas Usaha Kecil Menengah (UKM), kompetensi kewirausahaan inilah juga sangat diperlukan. Kompetensi kewirausahaan juga masih jarang diabahas terutama pada UKM. Maka, kami membahas klasifikasi,
\end{abstract}

Bisnis Dan Iptek | Sekolah Tinggi Ilmu Ekonomi Pasundan Bandung 
identifikasi dari beberapa publikasi ilmiah dan menganalisis pada literatur untuk menciptakan pemahaman secara rinci dalam bidang kompetensi kewirausahaan pada UKM. Kami menggunakan metode Systematic Mapping Study (SMS) untuk menelaah dari berbagai artikel di bidang komptenesi kewirausahaan pada UKM berdasarkan focus dan tipe riset dari waktu ke waktu. Hasil menunjukkan kategori dan kuantifikasi studi kompetensi kewirausahaan kedalam berbagai dimensi, juga ikhtisar topik dan tren penelitian kompetensi kewirausahaan pada UKM saat ini.

\section{Kata kunci: kompetensi kewirausahaan, usaha mikro kecil dan menengah, studi pemetaan sistematis.}

\section{PENDAHULUAN}

Kompetensi adalah konsep yang memiliki berbagai bentuk dan aplikasinya, dan model kompetensi kewirausahaan didasarkan pada berbagai pendekatan dan juga pengertian konsep kompetensi ini. Biasanya aspirasi untuk mencapai kerja yang superior, potensi, dan keuntungan atau kesuksesan bisnis atau ekonomi dapat mendorong pada penelitian dan praktik yang berkaitan dengan kompetensi (Spencer dan Spencer, 1993). Dengan banyaknya definisi lain dari kompetensi justru itu merupakan menjadi tantangan utama tersendiri dalam literatur kompetensinya (Van Overveld dan Van Goudoever, 1997; Bron, 1999; Hayton dan McEvoy, 2006; Hoffmann, 1999). Selanjutnya, istilah "keterampilan", "keahlian", "kecerdasan" dan "kompetensi" semuanya saling terkait dan kadangkadang digunakan secara bergantian dalam literatur (Smith dan Morse, 2005). Memang, pada tahun 1998, Hunt memperlihatkan bahwa perilaku yang kompeten dihasilkan dari berbagai faktor termasuk motivasi individu, ciri kepribadian, konsep diri, pengetahuan atau keterampilan dan oleh karena itu mungkin tidak mengherankan bahwa batas dan hubungan antara istilah-istilah ini tidak jelas. Ketidakjelasan tersebut selanjutnya didorong oleh penggunaan kompetensi konsep oleh berbagai pemangku kepentingan dengan tujuan yang berbeda (Burgoyne, 1993). Oleh karena itu, artikel ini melakukan tinjauan pustaka dari penelitian tentang kompetensi kewirausahaan untuk: memberikan akun terintegrasi dari kontribusi yang berkaitan dengan kompetensi kewirausahaan oleh penulis yang berbeda yang bekerja di berbagai negara dan sektor UKM dan pada titik waktu yang berbeda; dan, mengembangkan agenda untuk penelitian masa depan, dan praktek yang berkaitan dengan kompetensi kewirausahaan.

Dengan menggunakan metode Systematic Mapping Study, bisa dapat dipahami dari perspektif penelitian yang telah ada. Metode ini digunakan untuk memetakan penelitian-penelitian yang sudah ada terkait kompetensi kewirausahaan pada UKM pada Scopus. 
Tujuan dari metode ini untuk menggali wawasan yang lebih dalam dan membentuk latar belakang riset lebih lanjut tentang kajian kompetensi kewirausahaan, juga untuk akademisi dapat mengidentifikasi jarak penelitian di masa yang akan dating. Dari 252 artikel terkait kompetensi kewirausahaan hasil dari penelusuran di Scopus Database, metode SMS tepat digunakan sebagai pendekatan studi literatur. Untuk menguraikan jenis aktifitas penelitian yang telah dilakukan dalam penelitian ini diterapkannyalah SMS. SMS dapat menjelaskan penelitian pada tingkat tinggi serta dapat memetakan penelitian dari pada menyelidiki penelitian secara rinci (Petersen et al., 2008).

Pertanyaan penelitian (research question) dibutuhkan untuk mencapai penelitian yang lebih luas untuk menemukan temuan-temuan yang akurat dan juga relevan pada database Scopus. Peneliti secara keseluruhan menganalisis hasil pencarian yang relevan dengan kajian kompetensi kewirausahaan berdasarkan rumusan pertanyaan utama, meliputi:

1. Berapa banyak penelitian kompetensi kewirausahaan pada UKM, dari key string "Entrepreneurial Competences" pada Database Journal Electronic International Scopus?

2. Bagaimana tipe artikel dan metode penelitian yang digunakan?

3. Bagaimana perkembangan topik di setiap negara dan perkembangannya pada tahun-tahun sebelumnya?

\section{KERANGKA PEMIKIRAN}

Menurut Wibowo (2007:110) mengatakan bahwa kompetensi adalah suatu kemampuan yang dilandasi atas keterampilan dan juga pengetahuan untuk melaksanakan atau melakukan suatu pekerjaan serta didukung oleh sikap kerja yang dituntut oleh pekerjaan tersebut. Maka, kompetensi menunjukkan pengetahuan atau keterampilan pada suatu bidang tertentu oleh profesionalisme dengan indicator keterampilan, kemampuan dan sikap

Menurut Thomas W. Zimmerer dan Norman M. Scarbrough menyebutkan bahwa "wirausahawan adalah orang yang menciptakan bisnis baru dengan mengambil resiko dan ketidakpastian demi mencapai keuntungan dan pertumbuhan dengan cara mengidentifikasi peluang dan menggabungkan sumber daya yang diperlukan untuk mendirikannya". Peter Drucker berkata bahwa wirausaha tidak mencari resiko, mereka mencari peluang. 
Kompetensi kewirausahaan merupakan tiga indicator yang berhubungan satu sama lain yaitu pengetahuan, sikap, dan keterampilan yang diperlukan oleh pengusaha, pengusaha perlu melatih dan mengembangkannya agar bisa menghasilkan kinerja yang baik untuk mengelola usahanya. Keunggulan dimiliki seorang wirausahawan adalah kekuatan bagi dirinya dan juga usahanya serta harus sadar dan memperbaiki kelemahannya juga agar menciptakan keunggulan bersaing bagi usahanya (Suryana, 2013:90). Sedangkan menurut Fithri dan Amanda (2012:280) mengartikan kompetensi sebagai pengetahuan, keterampilan, dan kemampuan individu yang langsung berpengaruh pada kinerja. Sehingga pekerjaan atau kegiatan yang dilaksanakan oleh individu atau wirausaha yang memiliki ilmu pengetahuan, keterampilan, dan kualitas yang meliputi sikap, nilai, serta tingkah laku yang diperlukan akan berjalan dengan baik.

Disisi lain U.S Small Business Administration (SBA) Small Medium Enterprise atau UKM mengakatan "Usaha yang dimiliki dan dijalankan secara mandiri, didirikan untuk meraih keuntungan dan tidak dominan di bidangnya, serta menjual produk yang dihasilkan ke pelanggan di pasar lokal."

Setiap negara memiliki definisi yang berbeda mengenai UKM atau Small Medium Enterprise. Menurut UU No. 20 Tahun 2008, jenis usaha dibagi dalam dua pengertian, yaitu:

1. Usaha Kecil, merupakan entitas usaha yang memiliki kekayaan bersih lebih dari lima puluh juta rupiah sampai dengan paling banyak lima ratus juta rupiah, tidak termasuk tanah dan bangunan tempat usaha, serta memiliki hasil penjualan tahunan lebih dari tiga ratus juta rupiah sampai dengan paling banyak dua miliar lima ratus juta rupiah.

2. Usaha Menengah, merupakan entitas usaha yang memiliki kekayaan bersih lebih dari lima ratus juta rupiah sampai dengan paling banyak sepuluh miliar rupiah, tidak termasuk tanah dan bangunan tempat usaha, serta memiliki hasil penjualan tahunan lebih dari dua miliar lima ratus juta rupiah sampai dengan paling banyak lima puluh miliar rupiah.

Kompetensi kewirausahaan pada perusahaan sangat diperlukan dalam memberikan dampak guna menunjang aktivitas perusahaan, juga pada perusahaan usaha skala kecil menengah (UKM). Penelitian ini diharapkan dapat memicu munculnya penelitian-penelitian lain di bidang kompetensi kewirausahaan pada UKM. 


\section{DESAIN PENELITIAN}

Systematic mapping study telah diadopsi sebagai metodologi penelitian dalam studi ini, dengan mengikuti proses pemetaan sistematis yang dikemukakan oleh Petersen, Feldt, Mujtaba, dan Mattsson (2008). Tujuan dari studi pemetaan sistematis di sektor swasta adalah untuk memberikan pengamatan atas wilayah penelitian untuk menentukan apakah kata kunci pada topik penelitian telah diadopsi oleh sarjana lain di sektor swasta, dan untuk mengukur jumlah bukti yang berkaitan dengan topik penelitian (Kitchenham \& Charters, 2007).

Pedoman untuk tinjauan pustaka sistematis diterapkan seperti yang dijelaskan oleh Kitchenham dan Charters (2007) untuk mencari dan mengidentifikasi dokumen yang relevan. Parameter untuk melakukan proses pemetaan sistematis (Roberson, Holmes, \& Perry, 2017) dipilih untuk mencapai tujuan dalam mengeksplorasi studi yang ada terkait dengan konsep keberagaman.

Temuan studi ini akan memungkinkan kami untuk menemukan, mengkategorikan, dan merepresentasikan area penelitian terkait dengan keragaman di tempat kerja, serta potensi celah untuk investigasi lebih lanjut. Proses untuk studi pemetaan sistematis diartikulasikan dalam banyak tahap seperti yang dijelaskan pada gambar 1 .

Tahap pertama dalam proses pemetaan sistematis adalah untuk menggambarkan antara pertanyaan penelitian yang disebutkan di atas.

Langkah kedua studi pemetaan adalah mencari semua dokumen ilmiah yang relevan dengan topik penelitian. Protokol investigasi menetapkan metode yang akan diadopsi untuk melakukan eksplorasi literatur sistematis yang ditentukan dan untuk mengurangi kemungkinan bias peneliti (Kitchenham \& Charters, 2007).

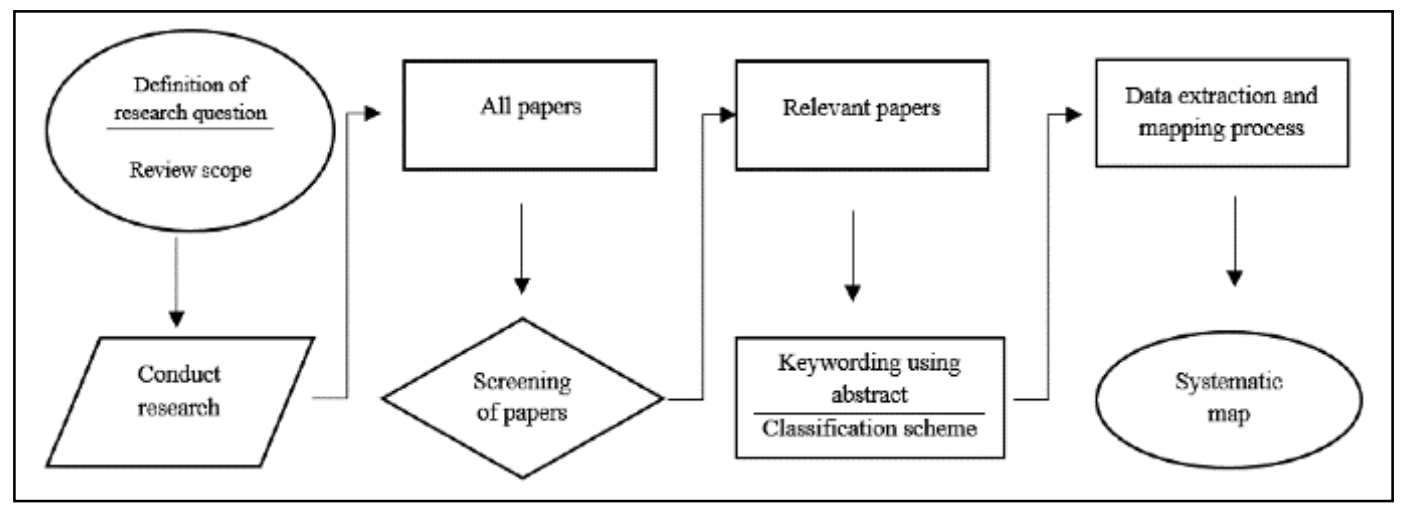

Gambar 1. Proses Pemetaan Sistematis

Prosedur penelitian telah dibuat untuk database ilmiah tertentu untuk mengumpulkan semua artikel yang relevan dengan topik penelitian. Kami 
menggunakan database Scopus karena relevansinya, interdisipliner, dan fokus pada kontribusi berkualitas tinggi yang ditinjau oleh sejawat yang diterbitkan dalam lokakarya, konferensi, jurnal, dan buku. Kami menggunakan pendekatan pengkodean terbuka (Corbin \& Strauss, 1990) untuk mengidentifikasi kata kunci yang akan digunakan dalam string pencarian "entrepreneurial competence" AND "Small and medium-sized enterprises".

\section{DETEKSI TEMA PENELITIAN}

Setelah menggunakan protokol penelitian dalam database ilmiah, tahap selanjutnya adalah pemilihan dokumen terkait yang kami terapkan dalam proses Dybå dan Dingsøyr (2008). Pada fase skrining pertama, artikel duplikat dikeluarkan. Selanjutnya, kami mengamati artikel berdasarkan judulnya dan menghilangkan studi yang tidak relevan dari penelitian tersebut. Tidak semua artikel yang dianalisis terkait erat dengan studi tentang entrepreneurial competence di UKM; oleh karena itu, artikel diperiksa untuk relevansi aktualnya (Kitchenham \& Charters, 2007). Protokol tersebut mencakup studi yang terkait dengan keragaman di berbagai bidang ilmiah yang mencakup berbagai makna dimensi keragaman entrepreneurial competence. Dokumen-dokumen ini secara eksplisit berada di luar tujuan studi pemetaan ini, dan ini akan menjadi alasan yang cukup untuk menghapusnya. Namun demikian, dalam beberapa situasi sulit untuk menentukan relevansi dokumen hanya berdasarkan judulnya. Dalam situasi seperti itu, dokumen dipindahkan ke tahap berikutnya untuk menjalani analisis lebih lanjut.

Tahap ketiga dibaca abstrak setiap artikel yang lolos tahap sebelumnya. Kriteria eksklusi dan inklusi yang akurat dikembangkan untuk memeriksa setiap artikel. Secara khusus, kami menolak publikasi dengan arti yang berbeda tentang dimensi entrepreneurial competence dari yang kami kembangkan, dan artikel di mana entrepreneurial competence dirujuk dalam konteks bisnis yang tidak dapat dibandingkan satu sama lain (misalnya, UKM) Setelah itu, artikel yang diidentifikasi yang dianggap terkait dengan topik ini dimasukkan ke dalam langkah penyaringan berikutnya.

Tahap selanjutnya dari studi pemetaan didasarkan pada kata kunci, sesuai dengan proses yang diusulkan oleh Petersen et al. (2008), yang mencakup dua fase. Pada tahap pertama, abstrak dibaca dan kata kunci serta kontribusi yang diberikan oleh artikel diakui (Petersen et al., 2008). Fase kedua melibatkan peningkatan pemahaman berdasarkan kata kunci yang disebutkan di atas. Yang terakhir ini memungkinkan kami untuk mengelompokkan item dan menyatakan kategori untuk memetakan jenis artikel yang relevan. Proses dilanjutkan dengan pembacaan dokumen terpilih. Karenanya, beberapa kategori telah diperbarui atau 
diperbaiki dan yang baru telah dibuat. Hal ini mengarah pada penjabaran peta sistematis kelas-kelas yang dikelompokkan yang dibentuk oleh semua artikel.

Tabel 1. Detail / Topik Ekstraksi Data

\begin{tabular}{|l|l|}
\hline \multicolumn{1}{|c|}{ Detail Data } & \multicolumn{1}{c|}{ Deskripsi } \\
\hline Study Identifier & Study ID \\
\hline Article Title & Title of Article \\
\hline Country & Country of Publication \\
\hline Year of Publication & Calender Year \\
\hline Publication Type & Type of Publication \\
\hline Publication Channels & Channels of Publication \\
\hline
\end{tabular}

\begin{tabular}{|l|l|}
\hline \multicolumn{1}{|c|}{ Paper Type } & \multicolumn{1}{c|}{ Penjelasan } \\
\hline Validation Research & $\begin{array}{l}\text { Metode investigasi baru dan belum diterapkan dalam praktik (percobaan } \\
\text { / observasi). }\end{array}$ \\
\hline Evaluation Research & $\begin{array}{l}\text { Metode investigasi diimplementasikan dalam praktik dan disajikan } \\
\text { dalam metode evaluasi. }\end{array}$ \\
\hline Solution Proposal & $\begin{array}{l}\text { Solusi untuk masalah diajukan, usulan solusi ini bisa berupa pendekatan } \\
\text { baru atau berlaku dan pendekatan yang ada. }\end{array}$ \\
\hline Philosophical Paper & $\begin{array}{l}\text { Penelitian ini memperkenalkan perspektif baru tentang sesuatu yang ada } \\
\text { dengan menggunakan taksonomi atau kerangka konseptual. }\end{array}$ \\
\hline Methods & \multicolumn{1}{c|}{ Penjelasan } \\
\hline Metode Kualitatif & $\begin{array}{l}\text { Metode Kualitatif disajikan Rapid Assessment Process, data sekunder, } \\
\text { etnografis, Focus Group Discussions, In-Depth Interviews, buku harian, } \\
\text { dan analisis bahasa. }\end{array}$ \\
\hline Metode Kuantitatif & $\begin{array}{l}\text { Metode Kuantitatif disajikan rancangan sampel, hipotesis dan } \\
\text { pengujiannya, yang semuanya berupa perumusan statistik. }\end{array}$ \\
\hline Mix Methods & $\begin{array}{l}\text { Metode yang memadukan pendekatan kualitatif dan kuantitatif dalam hal } \\
\text { metodologi (seperti dalam tahap pengumpulan data), dan kajian model } \\
\text { campuran memadukan dua pendekatan dalam semua tahapan proses } \\
\text { penelitian. }\end{array}$ \\
\hline
\end{tabular}

Sumber: Olahan Peneliti (2019); Petersen et al (2008).

Model ekstraksi data (Tabel 1) telah dipetakan untuk mengumpulkan informasi yang diperlukan untuk menjawab pertanyaan penelitian dari studi pemetaan (Petticrew \& Roberts, 2008). Informasi untuk setiap item yang diekstraksi telah ditabulasi dan diilustrasikan secara visual.

\section{ANALISIS KARAKTERISTIK PUBLIKASI}

Hasil proses seleksi disajikan pada Gambar 2. Secara khusus, 252 artikel awalnya dikumpulkan ketika protokol penelitian yang direncanakan dimasukkan ke dalam database ilmiah yang dipilih. Selanjutnya, tersisa 27 artikel pada penambahan kata kunci "Small and medium-sized enterprises". Pada langkah ketiga, kami mendapat 18 artikel setelah melakukan penghapusan duplikasi. Motivasi tingginya jumlah artikel yang dikecualikan terkait dengan topik penelitian. Secara khusus, banyak pasal yang dieliminasi berkaitan dengan entrepreneurial competence dalam kaitannya dengan layanan kesehatan atau bank, dan oleh karena itu, tidak sesuai 
dengan topik studi UKM. Banyak dokumen yang berkaitan dengan bidang ilmiah lain, seperti pertanian, bioteknologi, kimia, dan teknik, juga dihilangkan, karena istilah "entrepreneurial competence" dan "Small and medium-sized enterprises" memiliki arti yang berbeda dengan definisi sempit. Langkah ini mengarah pada identifikasi 12 artikel, yang dibaca dengan cermat. Sebanyak 2 artikel lagi ditinggalkan karena bidang tidak sesuai, Pada akhirnya, 10 publikasi diidentifikasi sebagai artikel utama.

\begin{tabular}{|c|c|}
\hline $\begin{array}{l}\text { Pencarian pada Database } \\
\text { Scopus } \\
\text { competence" }\end{array}$ & 252 Artikel \\
\hline $\begin{array}{l}\text { Memfokuskan pada kajian } \\
\text { SME "Small and medium- } \\
\text { sized enterprises" }\end{array}$ & 27 Artikel \\
\hline $\begin{array}{l}\text { Menghapus duplikasi kecuali } \\
\text { artikel, scholary jurnal dan } \\
\text { dalam bahasa Inggris }\end{array}$ & 18 Artikel \\
\hline $\begin{array}{l}\text { Menelaah dan membaca } \\
\text { judul, abstrak, dan keywords }\end{array}$ & 12 Artikel \\
\hline $\begin{array}{l}\text { Artikel akhir setelah di } \\
\text { analisis }\end{array}$ & 10 Artikel \\
\hline
\end{tabular}

\section{Gambar 2. Proses Penelitian dan Pemilihan Artikel}

\section{TAHUN TERBIT}

Gambar 3 menunjukkan tren numerik artikel yang diterbitkan selama periode 2008 hingga 2020. Hal tersebut didasarkan pada artikel-artikel yang termasuk sebagai artikel utama dalam penelitian ini. Peningkatan signifikan dalam publikasi tentang topik ini dapat diamati dari tahun 2016 karena entrepreneurial competence pada UKM yang semakin meningkat, yang semakin penting karena pemikiran produktif, motivasi, keterampilan interpersonal dan kepemimpinan. Ini menyoroti bahwa topik penelitian terus berkembang. Ini merupakan fenomena yang sudah relevan saat ini dan akan berdampak lebih besar di masa mendatang terhadap komposisi UKM. Dalam pengertian ini, perubahan terkait pengetahuan dan dinamika pekerja (Bruckner, 2012) akan menjadi elemen yang tidak boleh dianggap remeh oleh perusahaan dan organisasi. 
October , 2020

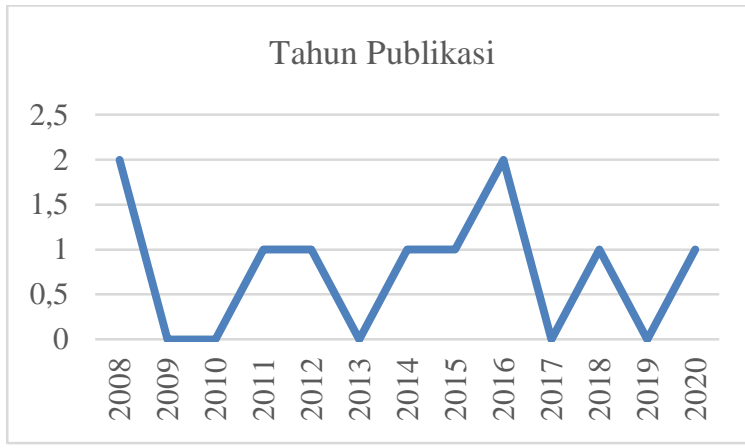

Gambar 3. Tahun Publikasi

\section{DISTRIBUSI GEOGRAFIS}

Pada Gambar 4 terlihat bahwa negara terbanyak yang menghasilkan artikel tentang entrepreneurial competence pada UKM yaitu Malaysia dengan total 4 artikel, diikuti Australia dan Russia dengan 2 artikel, selanjutnya Latvia dan Portugal dengan 2 artikel. Terlihat berdasarkan hasil pemetaan ini bahwa artikel mengenai entrepreneurial competence pada UKM bisa dibilang menarik terutama di negara-negara berkembang. Dengan jumlah artikel tersebut, diharapkan penelitian mengenai entrepreneurial competence pada UKM semakin banyak dan juga diharapkan mampu memberikan solusi dan dampak positif bagi pelaku usaha kecil dan menengah dalam menjalankan usahanya menjadi lebih baik.

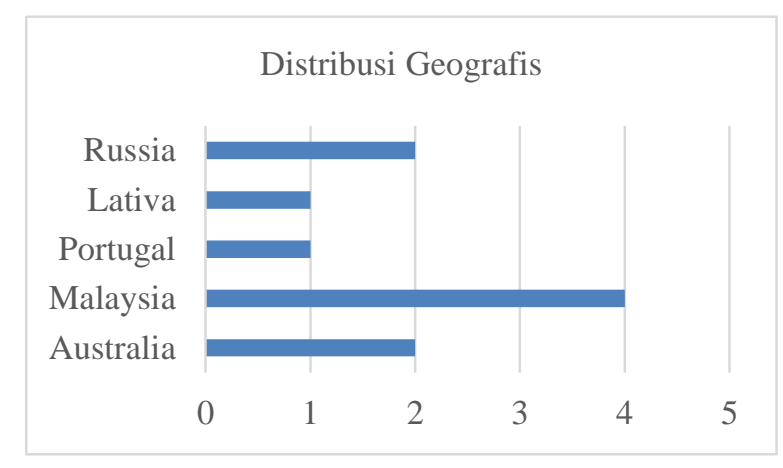

Gambar 4. Distribusi Geografis

\section{LANGKAH PENGKLASIFIKASIAN}

Langkah-langkah pada proses pemetaan sistematis, peneliti menganalisis dan mengklasifikasi artikel yang sudah terseleksi berdasarkan kriteria, yaitu berdasarkan fokus penelitian (Petersen et al., 2008), tipe artikel (Wieringa, Maiden, Mead, \&Rolland, 2006) dan penyebaran penelitian.

Setelah dilakukannya analisis lebih mendalam pada artikel yang ada berdasarkan kriteria yang telah dijelaskan pada Gambar 2, bahwa hasil akhir jurnal yang bisa dipetakan dengan kata kunci "entrepreneurial competence" dan "small and 
medium-sized entreprises" sebanyak 10 artikel, lalu dikelompokan dengan kategori methods, paper type, dan perkembangan penelitian dipenjuru dunia yang dipublikasi oleh Scopus menggunakan aplikasi Microsoft Excel.

\section{DISTRIBUSI JENIS PAPER}

Hasil pemetaan dari Gambar 2 total 252 artikel dengan keyword "entrepreneurial competence" pada Scopus terdapat 27 artikel entrepreneurial competence pada UKM yang telah dilakukan. Dengan jumlah tersebut, bisa dibilang artikel mengenai entrepreneurial competence pada UKM diharapkan dapat menarik para penelitian lain untuk melakukan penelitian dan mengisi jarak keilmuan publikasi dari jurnal tersebut agar dapat lebih luas dan menciptakan beragam pandangan dan temuan-temuan baru serta menambah keilmuan kompetensi kewirausahaan pada UKM. Pernyataan ini sesuai dengan pendapat Barbara Kitchenham (2004; 2007; 2009; 2011; 2013), bahwa SMS bertujuan untuk mengidentifikasi kesenjangan dalam penelitian saat ini dan memberikan saran untuk penyelidikan di masa yang akan dating, juga untuk memberikan latar belakang untuk memposisikan kegiatan penelitian baru.

\section{DISTRIBUSI METODE PENELITIAN}

Pada Gambar 5 menggambarkan distribusi tipe artikel (paper type) berdasarkan kategori pengklasifikasian menurut Wieringa et al. (2005). Berdasarkan hasil pemetaan secara sistematis (Systematic Mapping Study), tipe artikel yang paling sering digunakan adalah penelitian validasi (validation research) dengan total sebanyak $8(80 \%)$ dari total artikel penelitian kompetensi kewirausahaan pada UKM. Kemudian, tipe artikel yang paling sedikit adalah philoshophical paper dan evaluation research sebanyak $1(10 \%)$ dari total artikel penelitian kompetensi kewirausahaan pada UKM. Sedangkan tidak ada penelitian pada solution proposal.

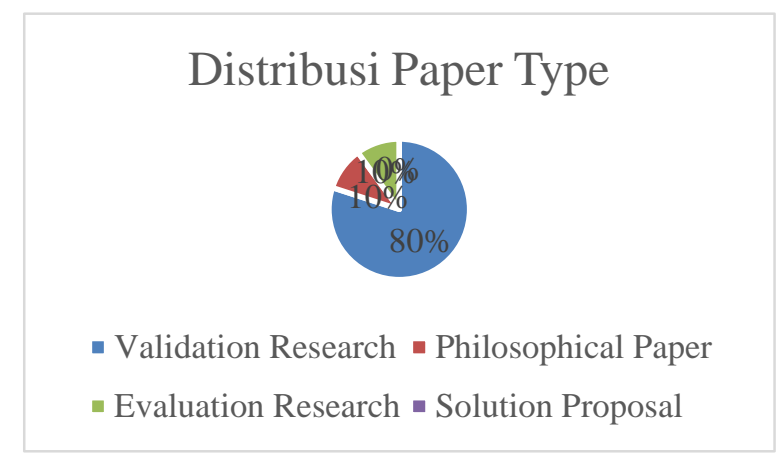

Gambar 5. Distribusi Jenis Paper

Total artikel pada Gambar 6 tersebut yang melakukan penelitian menggunakan pendekatan kuantitatif ada sebanyak 5 artikel (50\%) penelitian. Selanjutnya 
diikuti dengan artikel yang menggunakan metode kualitatif sebanyak 5 artikel (20\%) penelitian dan $30 \%$ artikel penelitian yang menggunakan mix methods.

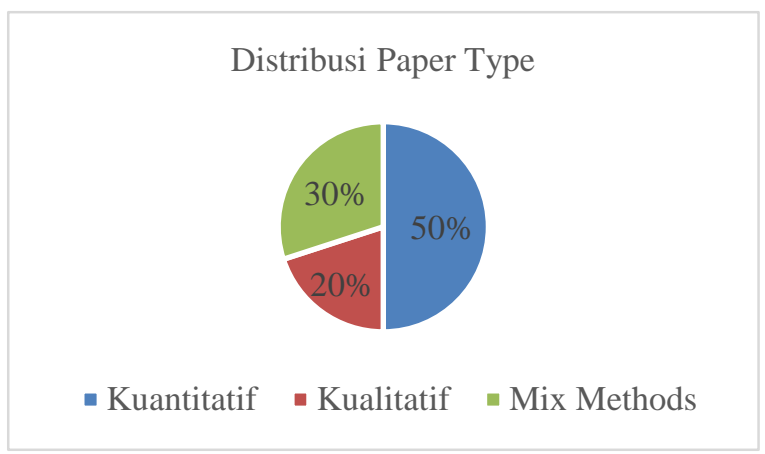

Gambar 6. Distribusi Metode Penelitian

\section{KESIMPULAN}

Dalam rangka meningkatkan daya saing dan juga kinerja yang baik di sector Usaha Kecil Menengah (UKM), perlu adanya penerapan konsep kompetensi kewirausahaan (Entrepreneurial Competence). Kompetensi kewirausahaan mampu memediasi penuh hubungan antara karakteristik kewirausahaan dan kinerja UKM dan pengaruh positif pada aktivitas usaha kecil menengah yang bergerak bersama-sama agar mampu bertahan dan bersaing dalam persaingan usaha. Hal ini penting agar mampu memberikan pengetahuan pada penggerak Usaha Kecil Menengah dalam menjalankan usahanya. Peran akademisi, praktisi, dan lembaga riset, serta pemerintah untuk menghasilkan kajian-kajian terkait kompetensi kewirausahaan merupakan suatu usaha agar mampu memberikan pengembangan konsep, gagasan dan ide tentang kompetensi kewirausahaan pada UKM.

Penelitian ini memetakan literatur kompetensi kewirausahaan pada UKM yang ada pada database ilmiah Scopus. Motivasi utama dari studi yang dipetakan adalah untuk memberikan gambaran umum literatur yang ada tentang kompetensi kewirausahaan pada UKM sebagai solusi untuk memenangkan persaingan usaha.

Peneliti menerapkan metode Systematic Mapping Study (Petersen et al., 2008; (Banaeianjahromi., N \& Smolander., 2016). Dari 10 artikel penelitian yang telah di petakan secara sistematik, kami menyimpulkan bahwa:

1. Hasil dari pemetaan pada Database Journal Electronic International Scopus dengan jumlah artikel keseluruhan 252 artikel, hanya 10 artikel yang melakukan penelitian mengenai kompetensi kewirausahaan pada UKM. 
Artinya masih banyak peluang untuk mengisi kekosongan atau kesenjangan penelitian mengenai kompetensi kewirausahaan pada UKM untuk diteliti.

2. Tipe artikel yang paling sering digunakan adalah penelitian validasi (validation research) dengan total sebanyak 8 (80\%) dari total artikel penelitian kompetensi kewirausahaan pada UKM Artinya masih banyak tipe penelitian yang belum banyak digunakan dan dapat menjadi peluang penelitian bagi peneliti lain untuk menambah khazanah penelitian dengan tipe penelitian yang beragam.

3. Negara terbanyak yang menghasilkan penelitian tentang kompetensi kewirausahaan pada UKM adalah Malaysia dengan total 4 publikasi. Dari hasil yang didapat, penelitian kompetensi kewirausahaan pada UKM ini banyak dilakukan pada negara-negara berkembang. Artinya penelitian mengenai kompetensi kewirausahaan pada UKM banyak berada di negaranegara berkembang.

Studi pemetaan sistematis ini mengacu pada dimensi keragaman kompetensi kewirausahaan pada UKM. Pemetaan sistematis memungkinkan untuk mengidentifikasi frekuensi publikasi dari waktu ke waktu dan di mana artikel tentang topik yang dikembangkan diterbitkan. Peta sistematis diadopsi sebagai langkah pertama menuju tinjauan sistematis, untuk membentuk gambaran yang jelas tentang topik dan, kemudian, untuk mengidentifikasi kesenjangan dalam penelitian. Kami melakukan studi pemetaan sistematis untuk memberikan analisis cluster penelitian tentang topik dan gambaran umum studi yang ada yang meneliti kompetensi kewirausahaan pada UKM.

Metode penelitian yang diadopsi SMS adalah metode penelitian praktis untuk mengenali topik yang tepat untuk diteliti, serta area mana yang diperlukan untuk lebih banyak penelitian. Hasil penelitian ini memberikan panduan untuk membantu peneliti dalam merencanakan penelitian di masa yang akan dating melalui penemuan kesenjangan penelitian gaps). Hal ini sesuai dengan pendapat Barbara Kitchenham, (2014; 2007; 2009; 2011; 2013), bahwa Systematic Mapping Study bertujuan untuk mengidentifikasi kesenjangan dalam penelitian saat ini dan memberikan saran untuk penyelidikan di masa depan, dan juga untuk memberikan latar belakang untuk mempromosikan kegiatan penelitian baru.

\section{REFERENSI}

Banaeianjahromi, N., \& Smolander, K. (2016). What Do We Know about The Role of Enterprise Architecture in Enterprise Integration? A Systematic 
Mapping Study. Journal of Enterprise Information Management, 29(1), 140-164. doi: https://doi.org/10.1108/JEIM-122014-0114.

Barbosa, O., \& Alves, C. (2011). A Systematic Mapping Study on Software Ecosystems. CEUR Workshop Proceedings, 746, 15-26.

Cragg, Paul Caldeira, Mário Ward, John (2011). Organizational information systems competences in small and medium-sized enterprises. Information and Management, 48(8), 353-363. doi: https://doi.org/10.1016/j.im.2011.08.003

Dybå, T., \& Dingsøyr, T. (2008). Empirical studies of agile software development: A systematic review. Information and Software Technology, 50 (9-10), 833-859. https://doi.org/10.1016/j.infsof.2008.01.006

Kitchenham, B., \& Charters, S. (2007). Guidelines for Performing Systematic Literature Reviews in Software Engineering (Version 2.3) EBSE Technical Report. Keele University and University of Durham.

Kitchenham, B., Brereton, O. P., Budgen, D., Turner, M., Bailey, J., \& Linkman, S. (2009). Systematic Literature Reviews in Software Engineering-A Systematic Literature Review. Information and Software Technology, 51(1), 7-15.

Kitchenham, B., \& Brereton, P. (2013). A Systematic Review of Systematic Review Process Research in Software Engineering. Information and Software Technology, 55(12), 2049-2075.

Kitchenham, B. (2004). Procedures for Performing Systematic Reviews. Keele, UK, Keele University, 33(2004), 1-26.

Muzychenko, Olga (2008). Competence-based approach to teaching international opportunity identification: cross-cultural aspects. European Journal of International Management, 2(1), 418-436. doi: https://doi.org/10.1504/EJIM.2008.021246

Ng, Hee Song Kee, Daisy Mui Hung Ramayah, Thurasamy (2016). The role of transformational leadership, entrepreneurial competence and technical competence on enterprise success of owner-managed SMEs. Journal of General Management, 42(1), 23-43. doi: https://doi.org/10.1177/030630701604200103

Petersen, K., Feldt, R., Mujtaba, S., \& Mattsson, M. (2008). Systematic mapping studies in software engineering. In Ease, 8, 68-77. https:// doi.org/10.14236/ewic/EASE2008.8

Petticrew, M., \& Roberts, H. (2008). Systematic reviews in the social sciences: A practical guide. John Wiley \& Sons. 
October , 2020

Wieringa, R., Maiden, N., Mead, N., \& Rolland, C. (2006). Requirements Engineering Paper Classification and Evaluation Criteria: A Proposal and A Discussion. Requirements Engineering, 11(1), 102-107. doi: https://doi.org/10.1007/s00766005-0021-6 